\title{
Electrochemical Studies of Betti Base and Its Copper(II) Complex by Cyclic and Elimination Voltammetry
}

\author{
Shardul Bhatt and Bhavna Trivedi \\ Department of Chemistry, Faculty of Science, The M.S. University of Baroda, Vadodara 390 002, India \\ Correspondence should be addressed to Bhavna Trivedi; trivedibhavna@yahoo.com
}

Received 30 September 2013; Accepted 3 November 2013

Academic Editor: Shengshui Hu

Copyright ( 92013 S. Bhatt and B. Trivedi. This is an open access article distributed under the Creative Commons Attribution License, which permits unrestricted use, distribution, and reproduction in any medium, provided the original work is properly cited.

\begin{abstract}
The electrochemical behavior of Betti base 1-( $\alpha$-amino benzyl)-2-naphthol (BB) and its copper(II) complex by cyclic and elimination voltammetry (EVLS) is reported in the present study. The cyclic voltammetric studies carried out at a glassy carbon working electrode, $\mathrm{Ag} / \mathrm{Ag}^{+}$reference electrode $\left(0.01 \mathrm{M} \mathrm{AgNO}_{3}\right.$ in acetonitrile) in DCM at $100 \mathrm{mV} / \mathrm{sec}, 200 \mathrm{mV} / \mathrm{sec}$, and $400 \mathrm{mV} / \mathrm{sec} \mathrm{scan}$ rates indicated a preceding chemical oxidation of the adsorbed BB species to form an iminium ion followed by formation of a carbanion via two-step quasireversible reduction. The suggested reaction mechanism has been supported by the elimination voltammetry. The $\mathrm{CV}$ and EVLS studies revealed $\mathrm{Cu}(\mathrm{II}) \mathrm{BB}$ complex to undergo a chemical or a surface reaction before electron transfer from the electrode at $-0.49 \mathrm{~V}$ to form $\mathrm{Cu}(\mathrm{I}) \mathrm{BB}$ species. The oxidation of $\mathrm{Cu}(\mathrm{I}) \mathrm{BB}$ species has been observed to be $\mathrm{CV}$ silent.
\end{abstract}

\section{Introduction}

The study of chemistry of Betti base (Figure 1) started in the beginning of the 20th century, when Betti reported the synthesis of 1-( $\alpha$-amino benzyl)-2-naphthol (Betti base, BB) [1] .

$\mathrm{BB}$ and its derivatives have been extensively used as auxiliary in catalytic reactions, particularly in addition of diethylzinc to arylaldehyde [2] and various coupling reactions like Mizoroki-Heck, Suzuki-Miyaura and Sonogashira [3]. It is suggested that the role of auxiliary amino ligands in Pd catalyzed reactions is to stabilize the catalytically active $\operatorname{Pd}(0)$ species [4]. This observation calls for an exhaustive investigation of the redox property of the ligand. $\mathrm{BB}$ with $-\mathrm{NH}_{2}$ and $\mathrm{OH}$ groups at 1 and 3 positions, respectively, is expected to act as an excellent ligand for coordination with transition metal ions, and $\mathrm{Cu}(\mathrm{II})$ complex with $\mathrm{BB}$ has been reported [5]. BB with $\mathrm{sp}^{3}$ hybridized carbon attached to phenyl ring, amine, and naphthol is expected to exhibit an interesting redox property.

Cyclic voltammetry is an excellent technique to probe chemical changes that occur as a result of electron transfer. One of the strengths of the CV technique is in the identification of electrochemical reactions involving combinations of electron transfer and chemical reaction steps through proper analysis of CV curves recorded at various scan rates. Many mathematical models have been proposed to extract useful information from the $\mathrm{CV}$ data [6] and elimination voltammetry is one such model. Elimination voltammetry with linear scan (EVLS), an electrochemical method comprising the elimination of some particular currents from the measurements of linear scan voltammetry was first proposed by Dracka and simultaneously verified by Trnkova in $1996[7,8]$. A large volume of work has been published by Trnková et al. [8-15]. Most of these papers point to EVLS as an excellent tool to understand electrochemical processes. It is successfully employed in the analysis of nucleic acids and short homo- or heterodeoxyoligonucleotides (ODNs) containing adenine (A) and cytosine (C) [15-17].

The simplicity and sensitivity of the elimination tool prompted us to explore its application to study electrochemical behavior of $\mathrm{BB}$ and its $\mathrm{Cu}(\mathrm{II})$ complex.

\section{Theory}

The EVLS can be considered as a transformation of currentpotential curves capable of eliminating some selected current components, while conserving others by means of elimination functions $[7,18]$. 


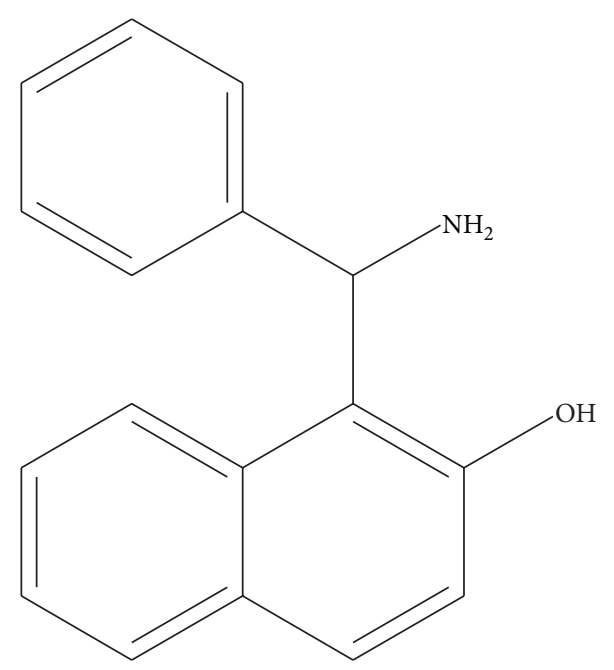

1-( $\alpha$-Amino benzyl)-2-naphthol

Figure 1: Betti base (BB).

The elimination function is based on rate dependence of various currents, that is, diffusion current, kinetic current, charging current, and so forth. Let $I$ be the total reference current measured at reference scan rate $v_{\text {ref }}$ and $I_{1 / 2}$ and $I_{2}$, the total currents measured at scan rates equal to one-half and twice of the reference current scan rate $\nu_{\text {ref }}$, respectively. The total currents recorded at the scan rates $(1 / 2) v_{\text {ref }}, v_{\text {ref }}$, and $2 v_{\text {ref }}$ can be given as

$$
\begin{gathered}
I_{1 / 2}=\left(I_{d}\right)_{1 / 2}+\left(I_{c}\right)_{1 / 2}+\left(I_{k}\right)_{1 / 2}, \\
I=\left(I_{d}\right)+\left(I_{c}\right)+\left(I_{k}\right), \\
I_{2}=\left(I_{d}\right)_{2}+\left(I_{c}\right)_{2}+\left(I_{k}\right)_{2} .
\end{gathered}
$$

Elimination is produced by the construction of a function of the total current $f(I)$ in the form of a linear combination of total currents, measured at different scan rates, and can be expressed as

$$
f(I)=a_{1} I_{1 / 2}+a_{2} I+a_{3} I_{2}
$$

With respect to nature of the simple currents shown, only the ratio of scan rate $v$ to the reference scan rate $v_{\text {ref }}$ is important. The total currents used in linear combination are then marked with an index expressing $\nu / \nu_{\text {ref }}$ ratios, so $I_{2}$, is the total current for $\nu / \nu_{\text {ref }}=2$ and so forth and can be expressed as:

$$
\begin{gathered}
a_{1} I_{1 / 2}=a_{1}\left(\frac{1}{2}\right)^{1 / 2}\left(I_{d}\right)+a_{1}\left(\frac{1}{2}\right)\left(I_{c}\right)+a_{1}\left(I_{k}\right), \\
a_{2} I=a_{2}\left(I_{d}\right)+a_{2}\left(I_{c}\right)+a_{2}\left(I_{k}\right), \\
a_{3} I_{2}=a_{3}(2)^{1 / 2}\left(I_{d}\right)+a_{3}(2)\left(I_{c}\right)+a_{3}\left(I_{k}\right) .
\end{gathered}
$$

For the conservation of diffusion current with simultaneous elimination of kinetic and charging currents the following requirements should be fulfilled:

$$
\begin{gathered}
a_{1}\left(\frac{1}{2}\right)^{1 / 2}\left(I_{d}\right)+a_{2}\left(I_{d}\right)+a_{3}(2)^{1 / 2}\left(I_{d}\right)=I_{d}, \\
a_{1}\left(\frac{1}{2}\right)\left(I_{c}\right)+a_{2}\left(I_{c}\right)+a_{3}(2)\left(I_{c}\right)=0, \\
a_{1}\left(I_{k}\right)+a_{2}\left(I_{k}\right)+a_{3}\left(I_{k}\right)=0 .
\end{gathered}
$$

The coefficients $a_{1}, a_{2}$, and $a_{3}$ can be obtained by solving the above three equations simultaneously using Matlab program $[9,19]$ and their values are calculated as

$$
a_{1}=-11.657 ; \quad a_{2}=17.485 ; \quad a_{3}=-5.8284
$$

Hence the elimination function for conservation of diffusion current with simultaneous elimination of kinetic and charging current can be given as E4 [7], simultaneous elimination of $I_{k}$ and $I_{c}$, with conservation of $I_{d}$ :

$$
f(I)=-11.657 I_{1 / 2}+17.485 I-5.8284 I_{2} .
$$

As a result of elimination, the reversible current of a substance transported to an electrode surface by diffusion only, is improved giving sharp peaks for reduction or oxidation signals. For the irreversible current of a fully adsorbed substance, this function provides the characteristic signal of a peak-to-counterpeak form, improving strongly the resolution and sensitivity $[7,14,15,18,20,21]$. Thus for the application of elimination voltammetry, all that is needed is voltammetric data at three scan rates. Once this data is fed into an appropriate elimination equation in MS Excel program, it generates information that is useful for understanding the electrochemical processes. 


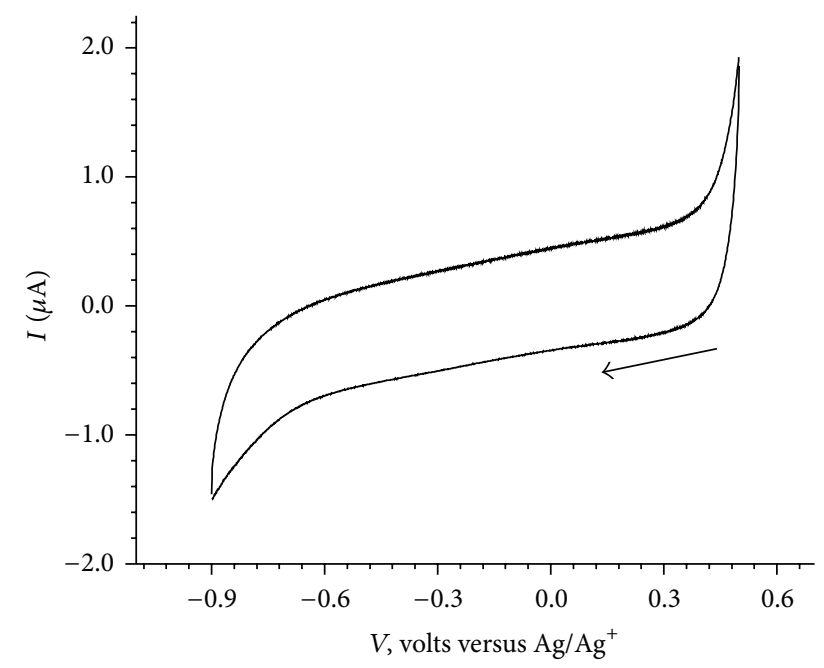

(a)

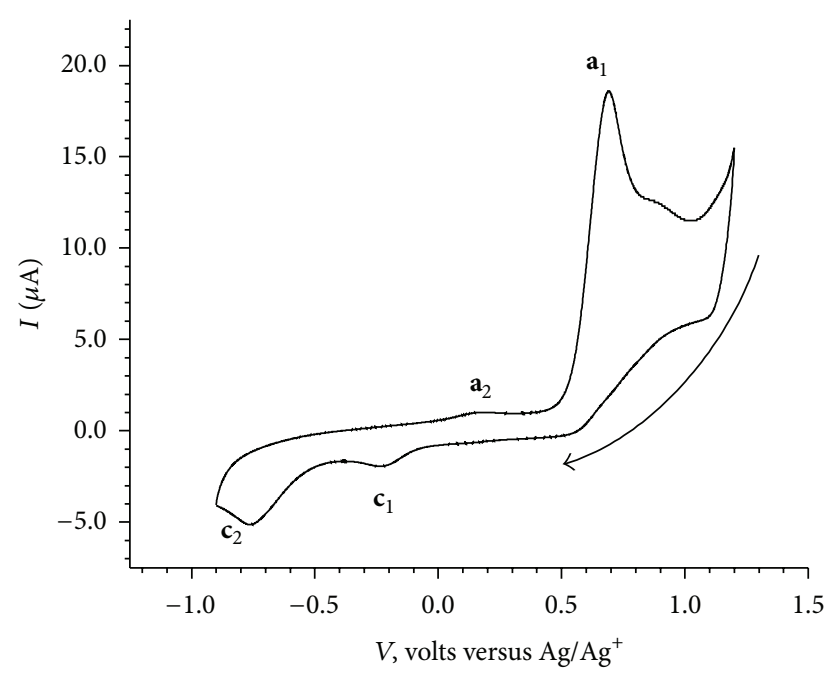

(b)

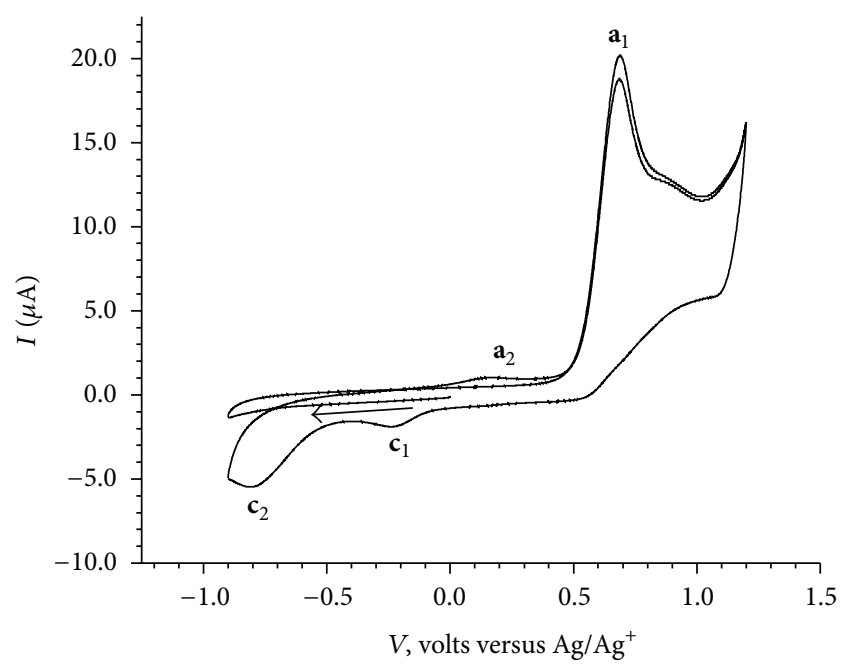

(c)

FIGURE 2: Cyclic voltammograms of Betti base (1 mM in DCM) using $0.1 \mathrm{M}$ tetra-n-butylammonium hexafluorophosphate as the supporting electrolyte. (a) $0.5 \mathrm{~V}$ to $-0.9 \mathrm{~V}$, (b) $1.2 \mathrm{~V}$ to $-0.9 \mathrm{~V}$, and (c) $0.0 \mathrm{~V}$ to $-0.9 \mathrm{~V}$.

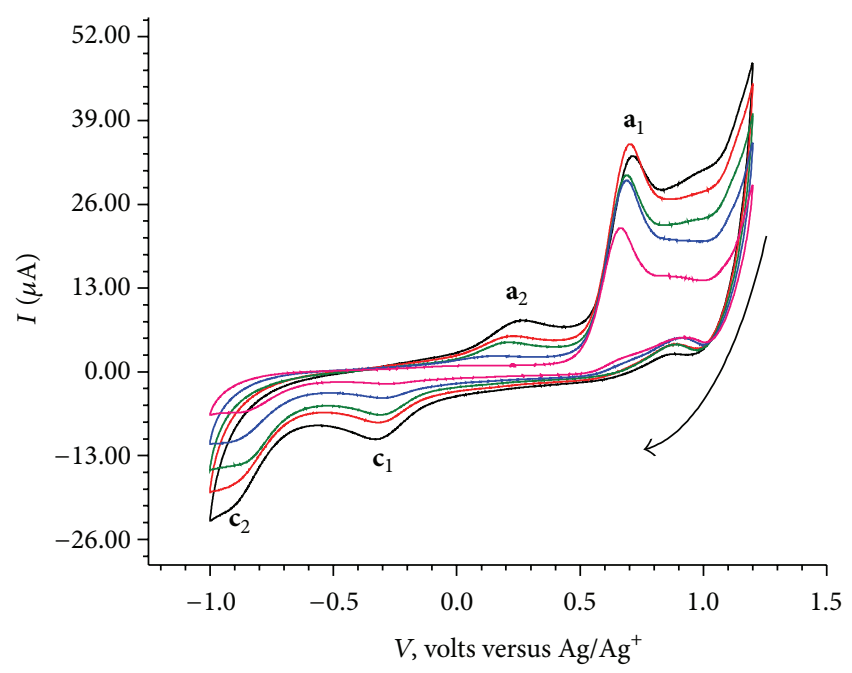

FIGURE 3: Cyclic voltammogram of the Betti base at increasing scan rate from 100 to $500 \mathrm{mV} / \mathrm{sec}$.

\section{Experimental}

3.1. Chemicals. BB was synthesized by the reported method [1]. Formation of BB was confirmed by elemental analysis, FTIR, ${ }^{1} \mathrm{H}$ NMR, and ${ }^{13} \mathrm{C}$ NMR spectroscopy.

3.2. Characterization of BB. M.P. $122-124^{\circ} \mathrm{C}$; reported M.P. $124^{\circ} \mathrm{C}$.

Anal. Calc. for $\mathrm{C}_{17} \mathrm{H}_{15} \mathrm{NO}$ (249.31): C, 81.8; H, 6.01; N, 5.6. Found: C, 81.43; H, 6.02; N, 5.55\%.

${ }^{1} \mathrm{H}$ NMR $\left(\mathrm{CDCl}_{3}\right)$ d: 7.67-7.70 (m, 3H), 7.13-7.42 (m, 8H), $6.10(\mathrm{~s}, 1 \mathrm{H}), 2.39$ (br s, 2H).

${ }^{13} \mathrm{C}$ NMR $\left(\mathrm{CDCl}_{3}\right)$ d: $156.9,142.4,132.0,129.7,129.0$, $128.7(2 \mathrm{C}), 128.5,127.9,127.3(2 \mathrm{C}), 126.4,122.4,121.2,120.5,115.1$, 55.9 .

IR $\left(\mathrm{KBr}, \mathrm{cm}^{-1}\right)$ : 3384, 3297, 3029, 1622, 1599, 1469, 1452.

UV (nm): $292(\varepsilon \sim 3500)$, b $337(\varepsilon \sim 2900)$.

All chemicals used were of AR grade. Freshly distilled solvents were employed for all synthetic purposes.

3.3. Synthesis of $\mathrm{Cu}(\mathrm{II}) \mathrm{BB}$ Complex. The $\mathrm{Cu}(\mathrm{II}) \mathrm{BB}$ complex was prepared by mixing $2 \mathrm{mM}$ solution of ligand in methanol with $1 \mathrm{mM}$ solution of $\mathrm{CuCl}_{2} \cdot 2 \mathrm{H}_{2} \mathrm{O}$. The mixture was stirred for $30 \mathrm{~min}$ at room temperature. The solid separated from the solution was collected on a Whatman filter paper, washed with small amount of methanol, and dried under vacuum. The purity of the isolated complex was confirmed by TLC (hexane : ethyl acetate; $5: 1$ ). No unreacted ligand was found. Further the complex was characterized by various spectral techniques like FT-IR, UV-Vis, elemental analysis, EPR, FABmass, and single crystal XRD [5].

3.4. Voltammetric Measurements. Electrochemical measurements were performed on a $\mathrm{CH}$ Instruments $600 \mathrm{C}$ potentiostat, with a glassy carbon as working electrode (area $\left.0.071 \mathrm{~cm}^{2}\right), \mathrm{Ag} / \mathrm{Ag}^{+}$reference electrode $\left(0.01 \mathrm{M} \mathrm{AgNO}_{3}\right.$ in acetonitrile, caution: keep vycor frit of reference electrode wet 


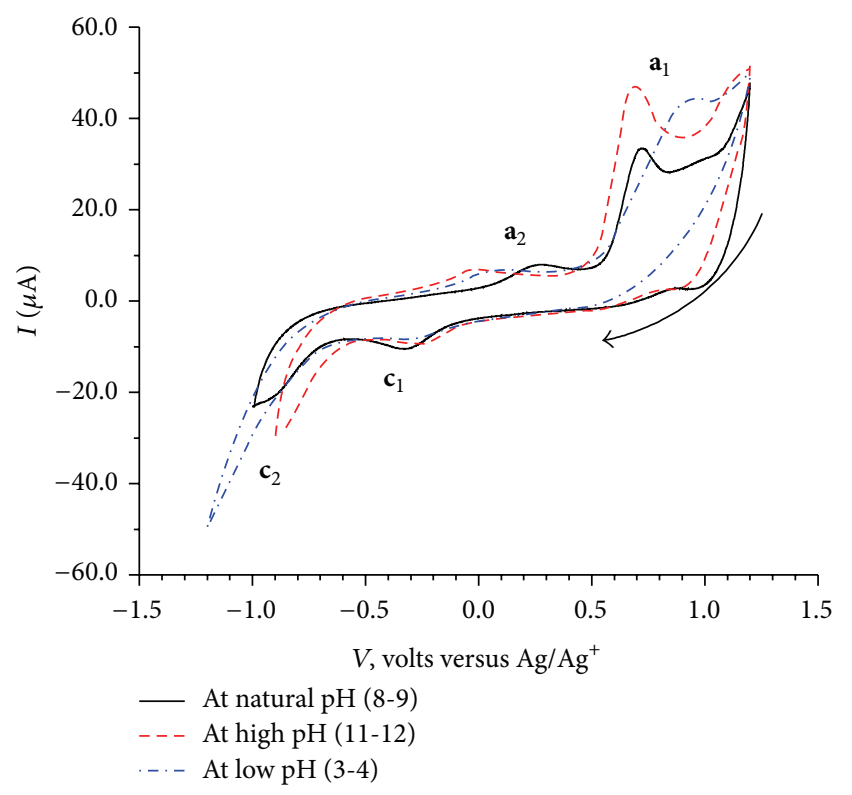

Figure 4: Cyclic voltammograms of a $1 \mathrm{mM}$ solution of $\mathrm{BB}$ in $\mathrm{DCM}$ at $300 \mathrm{mV} / \mathrm{sec}$ containing $0.1 \mathrm{M}$ tetra-n-butylammonium hexafluorophosphate as the supporting electrolyte.

to prevent the leakage of $\mathrm{AgNO}_{3}$ solution and frequently change the filled solution), and Pt wire as a counter electrode. To obtain reproducible results, the glassy carbon electrode was polished using polishing kit (CHI120) which consisted of a polishing polyurethane pad, alpha $\mathrm{Al}_{2} \mathrm{O}_{3}$ (particle size 1.0 and $0.3 \mu \mathrm{m}$ ), and gamma $\mathrm{Al}_{2} \mathrm{O}_{3}$ powder (particle size 0.05 $\mu \mathrm{m})$. The electrode was polished with $0.05 \mu \mathrm{m}$ alumina, sonicated (ultrasound bath) for $3 \mathrm{~min}$, and finally rinsed with deionized water before each measurement. Cyclic voltammetric studies were carried out using dichloromethane solution of $\mathrm{BB}$ and $\mathrm{Cu}(\mathrm{II}) \mathrm{BB}(1.0 \mathrm{mM})$ taking tetra-n-butyl ammonium hexafluorophosphate $(0.1 \mathrm{M})$ as the supporting electrolyte. Solutions were deoxygenated by bubbling dry nitrogen prior to the potential sweep. All experiments were carried out at room temperature.

3.5. Data Treatment. The voltammetric data was collected using CH600C Potentiostat instrument and exported to MS Excel for processing of elimination functions. The elimination function $f\left(I_{d}\right)$ has been selected for the evaluation of measurement,

$$
f\left(I_{d}\right)=-11.657 \times I_{1 / 2}+17.485 \times I-5.8284 \times I_{2} .
$$

\section{Results and Discussion}

4.1. Cyclic Voltammetry of BB. The cyclic voltammograms of $\mathrm{BB}(1.0 \mathrm{mM}, 100 \mathrm{mV} / \mathrm{sec})$ in the potential window of (A) $0.5 \mathrm{~V}$ to $-0.9 \mathrm{~V}$, (B) $1.2 \mathrm{~V}$ to $-0.9 \mathrm{~V}$, and (C) $0.0 \mathrm{~V}$ to $-0.9 \mathrm{~V}$ followed by reverse scan from $-0.9 \mathrm{~V}$ to $1.2 \mathrm{~V}$ and finally second cycle from 1.2 V to $-0.9 \mathrm{~V}$ are given in Figures 2(a), 2(b), and 2(c).

No significant electrochemical activity is observed in the potential range of $0.5 \mathrm{~V}$ to $-0.9 \mathrm{~V}$ (Figure $2(\mathrm{a})$ ). The $\mathrm{CV}$ of $\mathrm{BB}$

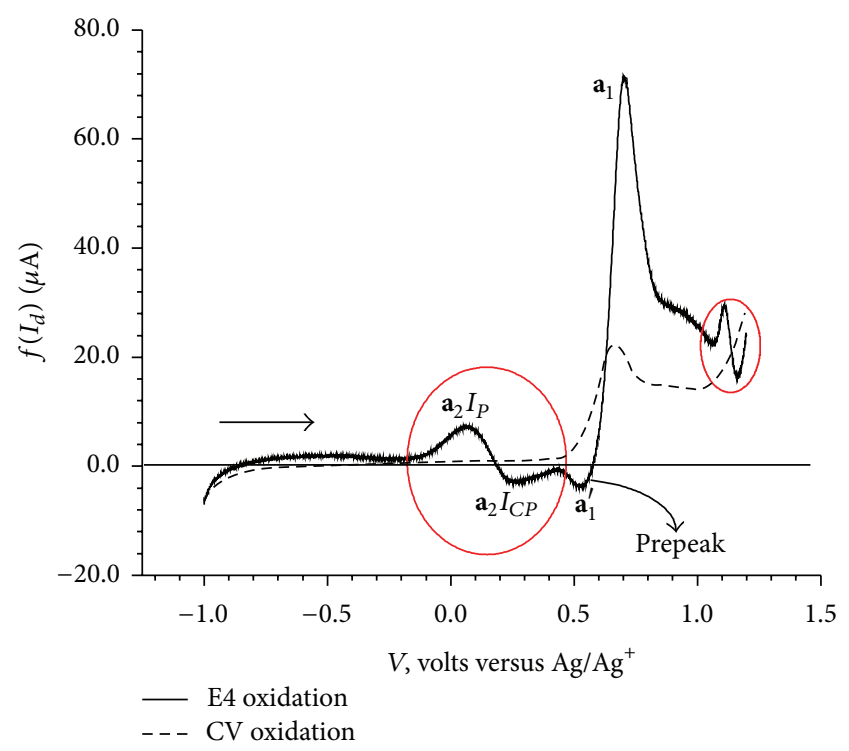

(a)

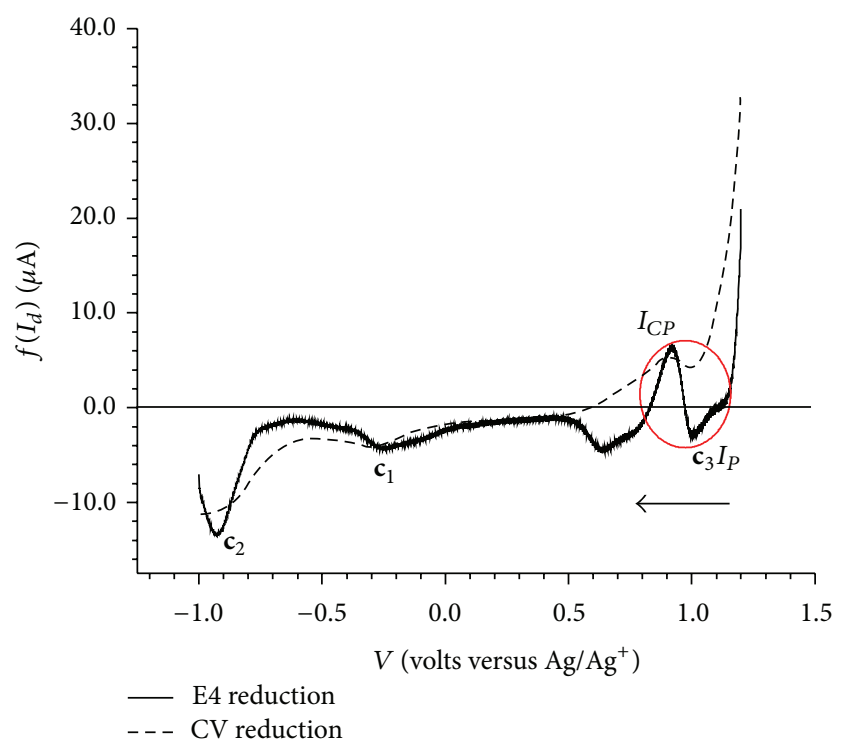

(b)

Figure 5: Plots for diffusion current $I_{d}$ for BB: (a) oxidation process and (b) reduction process.

exhibited two cathodic and two anodic peaks, when scanned from $1.2 \mathrm{~V}$ to $-0.9 \mathrm{~V}$ and back to $1.2 \mathrm{~V}$ (Figure 2(b)). However, as shown in Figure 2(c) no cathodic peak is observed when it is scanned from $0.0 \mathrm{~V}$ to $-0.9 \mathrm{~V}$; an anodic peak at $0.68 \mathrm{~V}$ appears on reversal of scan direction from $-0.9 \mathrm{~V}$ to $1.2 \mathrm{~V}$. Finally in the second cycle of $\mathrm{CV}$, from $1.2 \mathrm{~V}$ to $-0.9 \mathrm{~V}$ and back to $1.2 \mathrm{~V}$, it exhibited two cathodic ( $\mathbf{c}_{1}$ at $-0.2 \mathrm{~V}$ and $\mathbf{c}_{2}$ at $-0.8 \mathrm{~V}$ ) and two anodic peaks $\left(\mathbf{a}_{1}\right.$ at $0.68 \mathrm{~V}$ and $\mathbf{a}_{2}$ at $\left.0.17 \mathrm{~V}\right)$. The cyclic voltammograms recorded at various scan rates $(100 \mathrm{mV} / \mathrm{sec}$ to $500 \mathrm{mV} / \mathrm{sec})$ are shown in Figure 3. It reveals a small shift in peak potentials and increase in peak height with increase in scan rate.

CVs recorded at three different $\mathrm{pH}$ conditions are shown in Figure 4. 


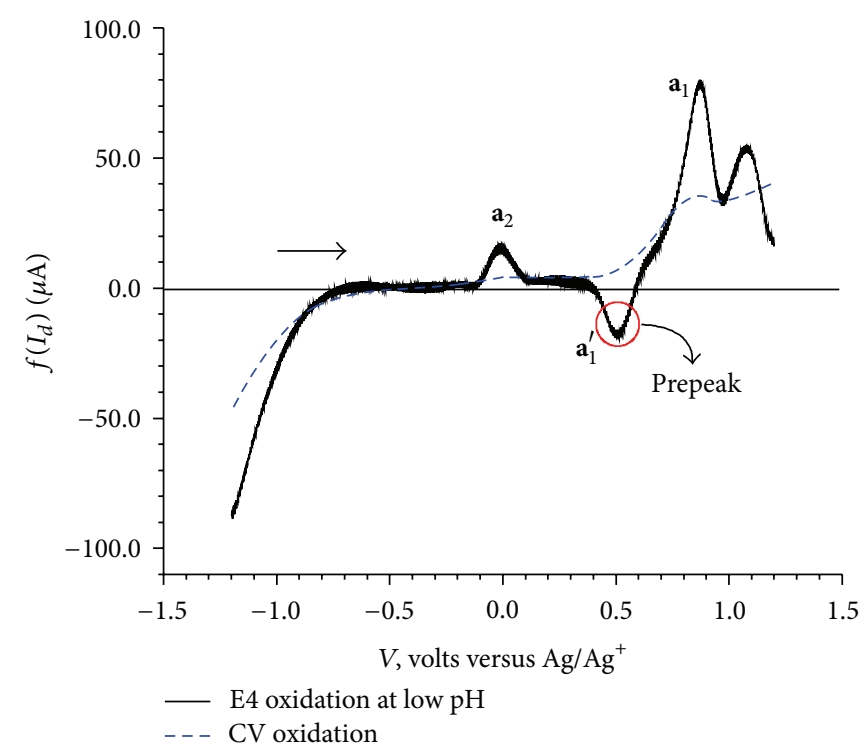

(a)

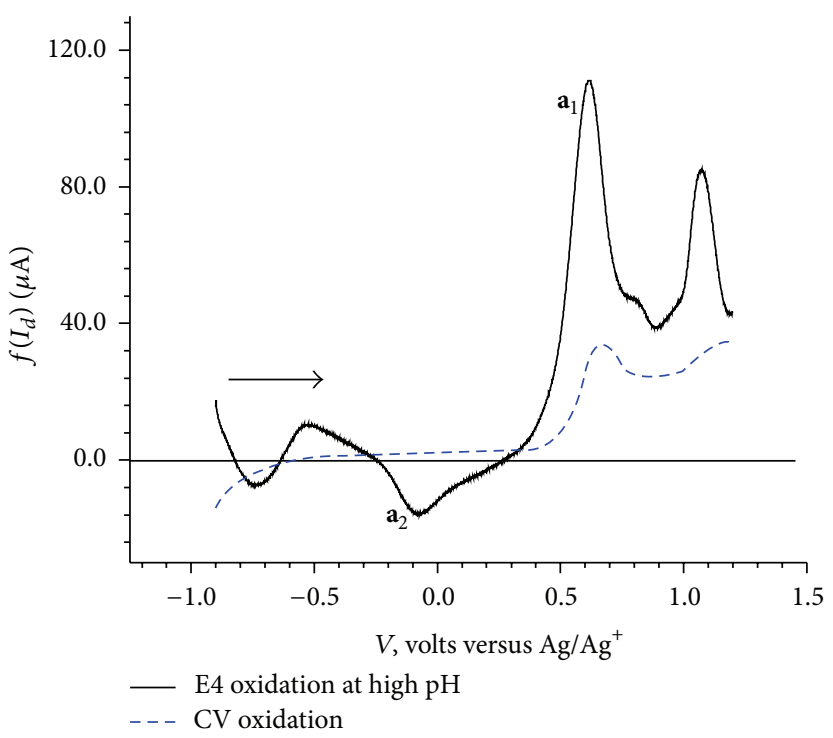

(b)

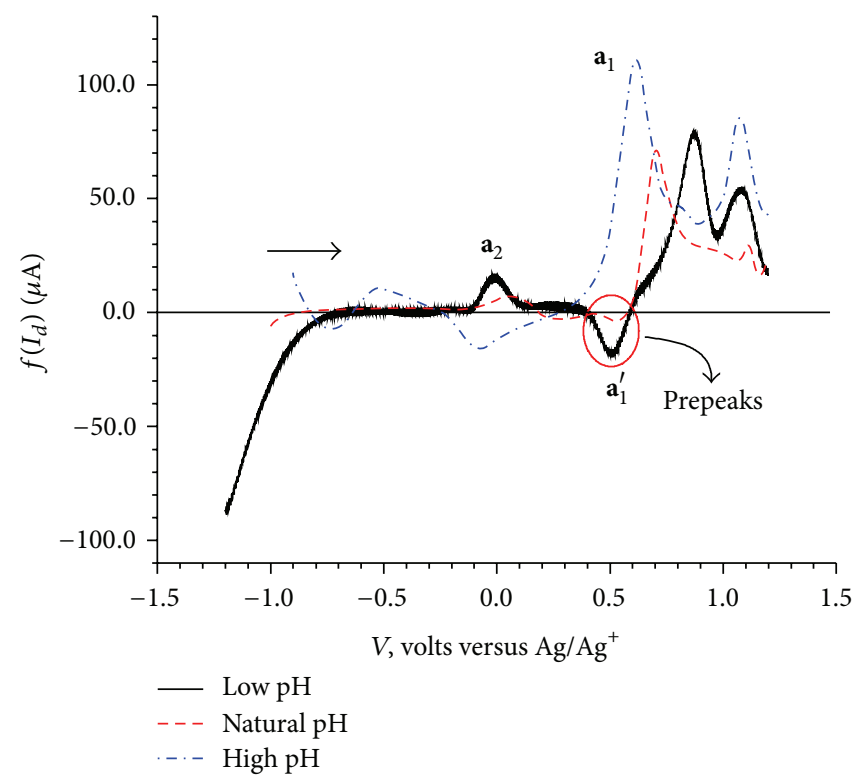

(c)

Figure 6: Plots for diffusion current $I_{d}$ for BB: (a) oxidation process at low $\mathrm{pH}$, (b) oxidation process at high $\mathrm{pH}$, and (c) overlay plot for oxidation process.

Figure 4 exhibits small changes in the peak potential values for the oxidation processes $\mathbf{a}_{1}$ and $\mathbf{a}_{2}$ and reduction process $\mathbf{c}_{2}$; however, the $\mathbf{c}_{1}$ reduction peak potential appears to be unaffected by the change in $\mathrm{pH}$.

Identification of the nature of currents involved in the electron transfer process, that is, diffusion, kinetic, or adsorptive would augment the understanding of the process, and as discussed above, the elimination voltammetry is the most appropriate tool for the purpose [12].

The elimination function which eliminates simultaneously charged and kinetic currents and conserves diffusion current [14].

Equation (7) was applied to the CV data obtained at three scan rates 100, 200 and $400 \mathrm{mV} / \mathrm{sec}$ considering $200 \mathrm{mV} / \mathrm{sec}$ as reference scan rate. For the sake of simplicity, the overlay curves of elimination function $f\left(I_{d}\right)$ and CV for the forward and reverse scans are displayed separately (Figures 5(a) and $5(\mathrm{~b}))$.

The elimination procedure resulted in a peak-counter peak $\left(\mathbf{a}_{2}\right)$ and a prepeak-peak $\left(\mathbf{a}_{1}^{\prime}\right.$ and $\mathbf{a}^{\mathbf{1}}$ ) (Figure 5(a)). The elimination function applied to the data for the reversed scans of $\mathrm{CV}$ resulted in two peaks, $\mathbf{c}_{\mathbf{1}}$ with no change in peak height and $\mathbf{c}_{2}$ with a small increase in peak height (Figure 5(b)). Apart from these two peaks, application of the $f\left(I_{d}\right)$ function resulted in a small peak-counter peak at $c_{3}$ (Figure 5(b)).

To understand the effect of $\mathrm{pH}$ on elimination function, the CV data were collected at three different scan rates 100 , 200 , and $400 \mathrm{mV} / \mathrm{sec}$ for each three $\mathrm{pH}$ conditions namely 


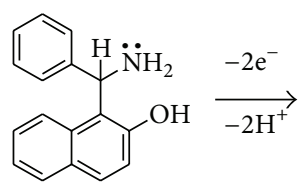

(I)

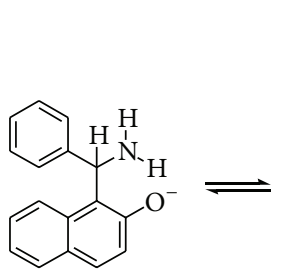

(VI)<smiles>[NH3+]c1ccc2ccccc2c1C([NH3+])(c1ccccc1)c1ccccc1[O-]</smiles>

(VII)<smiles>[N]=C(c1ccccc1)c1c(O)ccc2ccccc12</smiles>

(II)

(III)<smiles>CC[C+](C)C</smiles>

(IV)

Scheme 1: Proposed mechanism for the redox reaction of BB.

acidic, basic, and natural. The resulting elimination curves for anodic process are given in Figure 6.

On the basis of $\mathrm{CV}$ and elimination function data, the following mechanism is proposed (Scheme 1).

The dependence of the overall redox process on the high positive values of the initial potential 1.2 V (Figure 2(c)) indicates a need of overpotential to increase the charge transfer for the formation of a species II $\left(\mathbf{a}_{\mathbf{1}}\right)$ as the first step at $0.68 \mathrm{~V}$. This step might be controlled by either mass transport diffusion processes or a preceding chemical reaction associated with the charge transfer reaction giving kinetic current or may be a combination of both. The appearance of the prepeak $\mathbf{a}_{1}^{\prime}$ (Figure 5(a)) in the elimination curve may be due to proton transfer followed by electron transfer. This is further confirmed by the $\mathrm{pH}$ dependence of peak $\mathbf{a}_{\mathbf{1}}$ in the $\mathrm{CV}$ (Figure 4) and prepeak $\mathbf{a}_{1}^{\prime}$ in the EVLS curves (Figures 6(a) and 6(c)). The decrease in prepeak currents with the increase in $\mathrm{pH}$ (Figure 6(c)) indicates decreased tendency of proton transfer prior to the electron transfer. A complete disappearance of the prepeak and increased height of the peak $a_{1}$ at alkaline $\mathrm{pH}$ in the EVLS (Figure 6(b)) hint towards a possibility of simultaneous transfer of proton and electron. The species II is in equilibrium with a protonated iminium ion III which undergoes reduction at $-0.24 \mathrm{~V}\left(c_{1}\right.$, Figure $\left.2(\mathrm{~b})\right)$ to form a radical IV. The radical IV is further reduced to form a benzylic carbanion $\mathbf{V}\left(\mathbf{c}_{2}\right.$, Figure $\left.2(\mathrm{~b})\right)$. The benzylic anion would be expected to quickly equilibrate to the phenoxide. This step is $\mathrm{pH}$ dependent. A similar electrochemical study of proton coupled electron transfer mechanism has been reviewed by Costentin et al. [22]. The final step is the oxidation of $\mathrm{VI}$ at $0.17 \mathrm{~V}\left(\mathbf{a}_{\mathbf{2}}\right)$ to give an amine cation radical VII.
As exhibited in Figure 4, the oxidation of VI to VII is $\mathrm{pH}$ dependent step. The EVLS curve obtained on application of $f\left(I_{d}\right)$ (Figure 5(a)) exhibits increased height of $\mathbf{a}_{2}$ indicating a quasi-reversible diffusion controlled process [14].

4.2. The Electrochemical Study of $\mathrm{Cu}(\mathrm{II}) \mathrm{BB}$. The ORTEP diagram of $\mathrm{Cu}$ (II)BB as reported [5] is given as inset in Scheme 2 for the reference. As can be seen from the diagram the copper atom is bonded to two-nitrogen and two-oxygen atoms; both pairs are in trans position with a perfect square planer geometry around copper.

The cyclic voltammogram for the isolated complex $\mathrm{Cu}(\mathrm{II}) \mathrm{BB}$ as shown in Figure 7(a), exhibited an anodic peak at $0.33 \mathrm{~V}$ followed by a cathodic peak at $-0.49 \mathrm{~V}$. The elimination function E4 (7) applied to the CV data collected at three scanning rates 100, 200 and $400 \mathrm{mV} / \mathrm{sec}[7,8,16,18]$ for the oxidation process resulted in a prepeak $\left(x^{\prime}\right)$ and peak-counter peak $(x),\left(x^{\prime \prime}\right)$ as depicted in Figure $7(\mathrm{c})$. The application of elimination function $\mathrm{E} 4$ resulted in a prepeak-peak $\mathbf{c}_{\mathbf{1}}^{\prime}$ and $\mathbf{c}_{\mathbf{1}}$ as shown in Figure $7(\mathrm{~d})$.

On the basis of the above observations, a redox mechanism for $\mathrm{Cu}(\mathrm{II}) \mathrm{BB}$ has been proposed as Scheme 2 .

The oxidation of the adsorbed ligand is the first step as indicated by the appearance of prepeak-peak at $0.25 \mathrm{~V}$ in the EVLS (inset Figure 7(c)). This observation is similar to the oxidation of the ligand with potential values shifted to less positive values as expected due to the charge transfer from the ligand on coordination to the metal ion. This is followed by reduction of the metal ion from $\mathrm{Cu}$ (II) to $\mathrm{Cu}(\mathrm{I})$ at $\mathbf{c}_{\mathbf{1}}$ which appears as prepeak-peak in EVLS (Figure $7(\mathrm{~d})$ ). The appearance of prepeak indicates a chemical or a surface reaction 


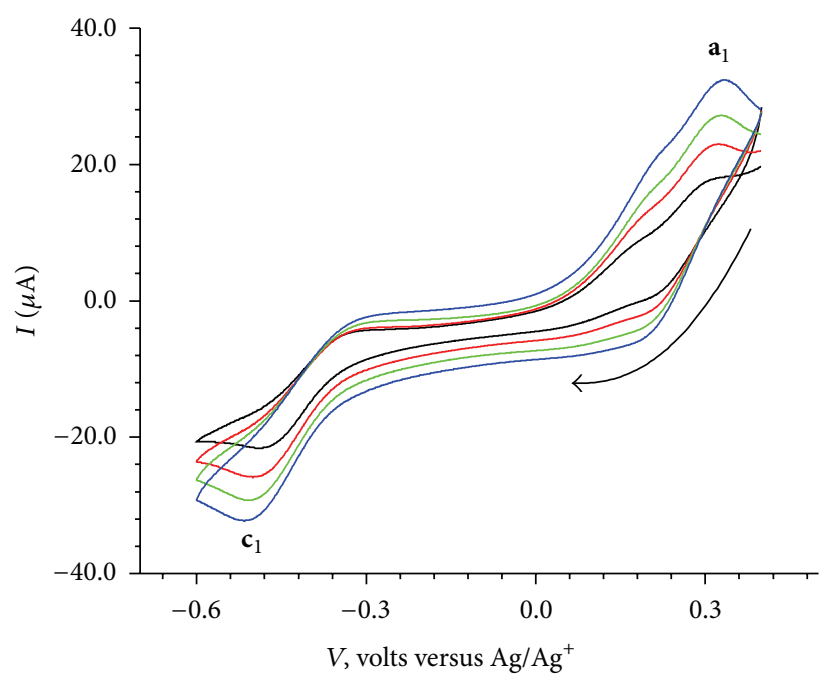

(a)

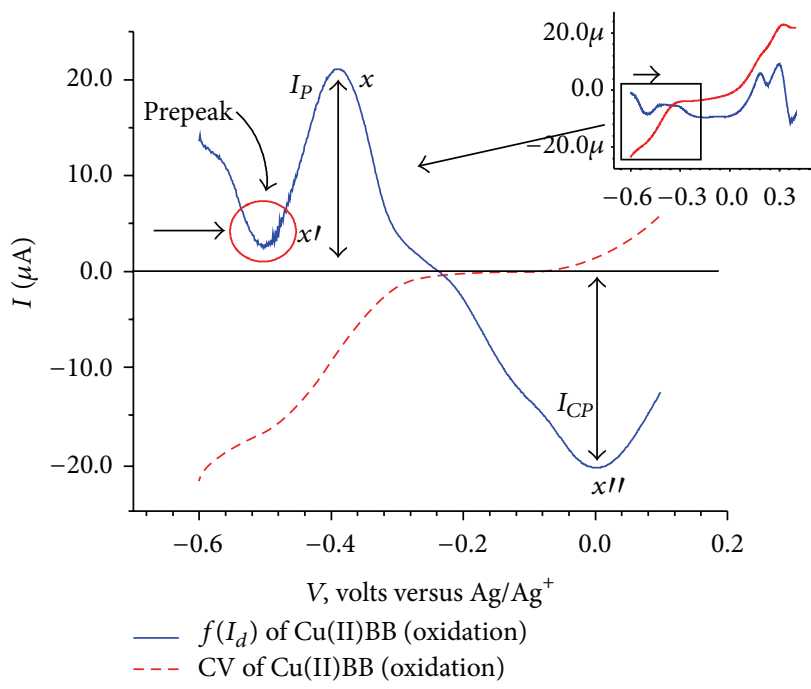

(c)

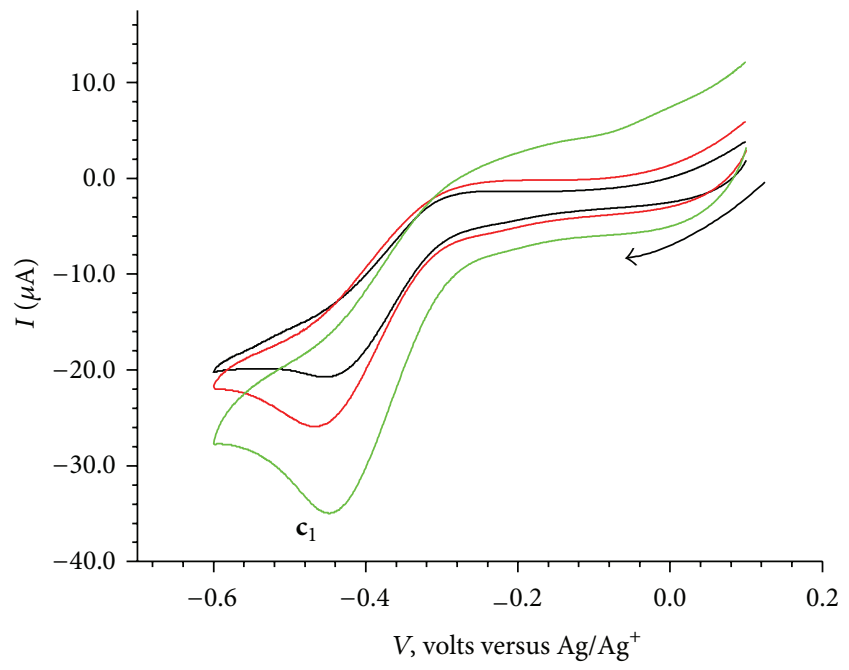

(b)

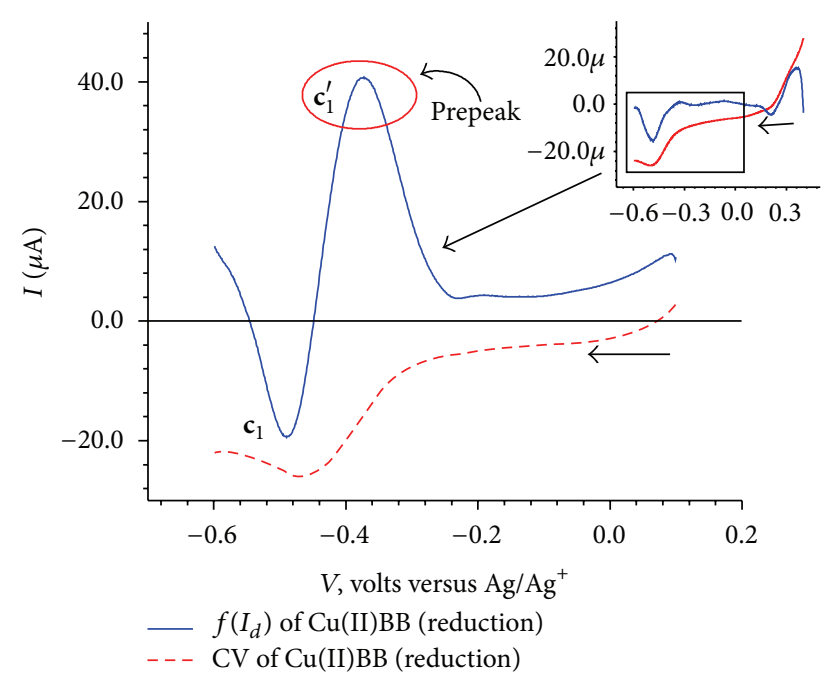

(d)

Figure 7: (a) and (b) cyclic voltammogram of $\mathrm{Cu}(\mathrm{II}) \mathrm{BB}$ with increasing scan rate $100 \mathrm{mV} / \mathrm{sec}$ to $400 \mathrm{mV} / \mathrm{sec}$, (c) $f\left(I_{d}\right)$ elimination plot for the oxidation of $\mathrm{Cu}(\mathrm{II})$ complex, and (d) $f\left(I_{d}\right)$ elimination plot for the reduction of $\mathrm{Cu}$ (II) complex.

before electron transfer. As can be seen from the voltammogram (Figure $7(\mathrm{~b})$ ), the peak corresponding to oxidation of copper is not observed. This could be due to intramolecular electron transfer via valence tautomerism between electroactive ligand and metal ion [23-26] causing fast disproportionation of $\mathrm{Cu}$ (I) complex to give $\mathrm{Cu}$ (II) or some rearrangement within complex so as to give a more stabilized species. However the EVLS curves (Figure $7(\mathrm{c})$ ) exhibits prepeakpeak at $x^{\prime}$ and $x$ followed by a counterpeak indicating some chemical or a surface reaction prior to diffusion of the species in the adsorbed state [18]. With the help of CV and EVLS it can be proved that the $\mathrm{Cu}(\mathrm{II}) \mathrm{BB}$ complex follows CEC mechanism.

\section{Conclusion}

This is the first paper where the EVLS technique is applied to study the electrochemical behavior of a metal complex. EVLS has been found to be the best tool to understand the CV silent chemical processes. It can be concluded from the $\mathrm{CV}$ and EVLS data that the BB follows CEE where as $\mathrm{Cu}$ (II)BB complex follows CEC mechanism. The electrochemical study of $\mathrm{BB}$ can be useful to enlarge the range of functionality of the derivatives of Betti bases for the organic synthesis. FT-IR, ${ }^{1} \mathrm{H}$ NMR and ${ }^{13} \mathrm{C}$ NMR spectra of Betti base are given as supporting information in Supplementary Material available online at http://dx.doi.org/10.1155/2013/678013. 


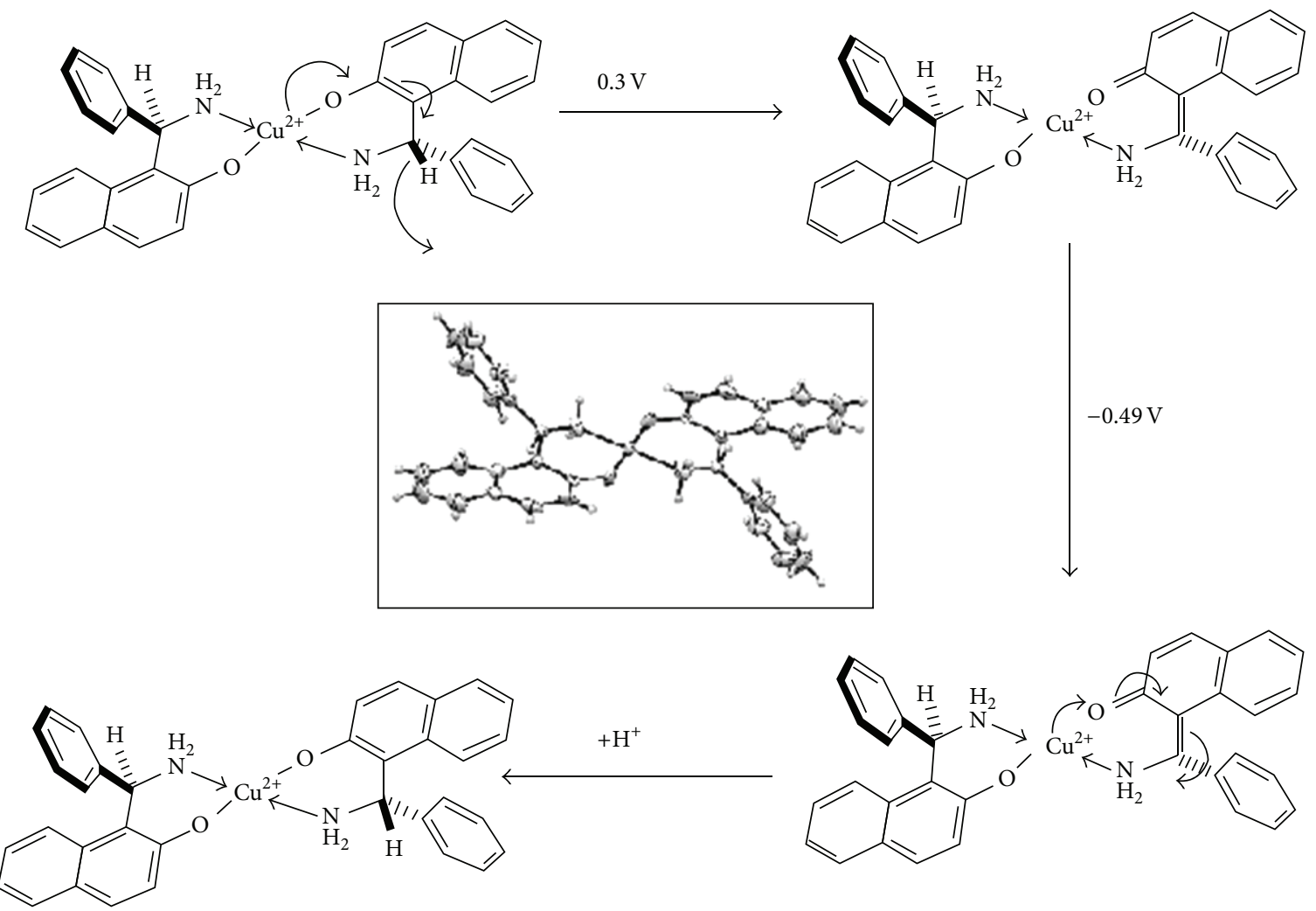

Scheme 2: Proposed mechanism for the redox reaction of $\mathrm{Cu}(\mathrm{II}) \mathrm{BB}$.

\section{Conflict of Interests}

The authors declare that there is no conflict of interests regarding the publication of this paper.

\section{Acknowledgments}

Mr. Shardul Bhatt is thankful to University Grant Commission (UGC, F.33-254/2007 28-2-2008(SR)) and CSIR (09/114/(0192)/2013/EMR-I), New Delhi for financial support. The authors are thankful to the Head Chemistry Department, The M.S. University of Baroda for providing the infrastructural facilities.

\section{References}

[1] M. Betti, "Synthesis of Betti base," Organic Syntheses Collective, vol. 1, pp. 381-383, 1941.

[2] C. Cimarelli, G. Palmieri, and E. Volpini, "A practical stereoselective synthesis of secondary and tertiary aminonaphthols: chiral ligands for enantioselective catalysts in the addition of diethylzinc to benzaldehyde," Tetrahedron Asymmetry, vol. 13, no. 22, pp. 2417-2426, 2002.

[3] A. R. Chaudhary and A. V. Bedekar, "Sunlight promoted palladium catalyzed Mizoroki-Heck, Suzuki-Miyaura and Sonogashira reactions," Tetrahedron Letters, vol. 53, pp. 6100-6103, 2012.

[4] B. Tao and D. W. Boykin, "Simple amine/Pd(OAc) $)_{2}$-catalyzed Suzuki coupling reactions of aryl bromides under mild aerobic conditions," Journal of Organic Chemistry, vol. 69, no. 13, pp. 4330-4335, 2004.

[5] S. Bhatt and B. Trivedi, "Synthesis and characterization of some novel copper(II) complexes with an optically active Betti base," Polyhedron, vol. 35, no. 1, pp. 15-22, 2012.

[6] A. J. Bard and L. R. Faulkner, Electrochemical Methods, Fundamentals and Applications, John Wiley \& Sons, New York, NY, USA, 1980

[7] O. Dračka, "Theory of current elimination in linear scan voltammetry," Journal of Electroanalytical Chemistry, vol. 402, no. 1-2, pp. 19-28, 1996.

[8] L. Trnková and O. Dračka, "Elimination voltammetry. Experimental verification and extension of theoretical results," Journal of Electroanalytical Chemistry, vol. 413, no. 1-2, pp. 123-129, 1996.

[9] N. Serrano, A. Alberich, and L. Trnkova, "Oxidation of 6-benzylaminopurine-copper(I) complex on pencil graphite electrode," Electroanalysis, vol. 24, no. 4, pp. 955-960, 2012.

[10] L. Trnkova, L. Zerzankova, F. Dycka, R. Mikelova, and F. Jelen, "Study of copper and purine-copper complexes on modified carbon electrodes by cyclic and elimination voltammetry," Sensors, vol. 8, no. 1, pp. 429-444, 2008.

[11] M. Šupicová, R. Rozik, L. Trnková, R. Oriňáková, and M. Gálová, "Influence of boric acid on the electrochemical deposition of Ni," Journal of Solid State Electrochemistry, vol. 10, no. 2, pp. 61-68, 2006.

[12] L. Trnková, I. Postbieglová, and M. Holik, "Electroanalytical determination of d(GCGAAGC) hairpin," Bioelectrochemistry, vol. 63, no. 1-2, pp. 25-30, 2004. 
[13] L. Trnková, "Electrochemical behavior of DNA at a silver electrode studied by cyclic and elimination voltammetry," Talanta, vol. 56, no. 5, pp. 887-894, 2002.

[14] L. Trnkova, R. Kizek, V. Adam, T. Eckschlager, and J. Hubalek, Sensing in Electroanalysis, vol. 5, University Press Centre, Pardubice, Czech Republic, 2010.

[15] L. Trnková, F. Jelen, and I. Postbieglová, “Application of elimination voltammetry to the resolution of adenine and cytosine signals in oligonucleotides II. Hetero-oligodeoxynucleotides with different sequences of adenine and cytosine nucleotides," Electroanalysis, vol. 18, no. 7, pp. 662-669, 2006.

[16] L. Trnková, F. Jelen, and I. Postbieglová, “Application of elimination voltammetry to the resolution of adenine and cytosine signals in oligonucleotides. I. Homo-oligodeoxynucleotides dA 9 and dC9," Electroanalysis, vol. 15, no. 19, pp. 1529-1535, 2003.

[17] L. Trnkova, F. Jelen, J. Petrlova, V. Adam, D. Potesil, and R. Kizek, "Elimination voltammetry with linear scan as a new detection method for DNA sensors," Sensors, vol. 5, no. 6-10, pp. 448-464, 2005.

[18] L. Trnková, "Identification of current nature by elimination voltammetry with linear scan," Journal of Electroanalytical Chemistry, vol. 582, no. 1-2, pp. 258-266, 2005.

[19] Matlab Version 7.3.0.267, Mathworks Inc., Natick, Mass, USA, 2006.

[20] F. Jelen, A. Kourilova, S. Hason, R. Kizek, and L. Trnkova, "Voltammetric study of adenine complex with copper on mercury electrode," Electroanalysis, vol. 21, no. 3-5, pp. 439-444, 2009.

[21] N. Aladag, L. Trnkova, A. Kourilova, M. Ozsoz, and F. Jelen, "Voltammetric study of aminopurines on pencil graphite electrode in the presence of copper ions," Electroanalysis, vol. 22, no. 15, pp. 1675-1681, 2010.

[22] C. Costentin, M. Robert, and J.-M. Savéant, "Update 1 of: electrochemical approach to the mechanistic study of proton-coupled electron transfer," Chemical Reviews, vol. 110, no. 12, pp. PR1-PR40, 2010.

[23] E. Evangelio and D. Ruiz-Molina, "Valence tautomerism: more actors than just electroactive ligands and metal ions," Comptes Rendus Chimie, vol. 11, no. 10, pp. 1137-1154, 2008.

[24] E. Evangelio and D. Ruiz-Molina, "Valence tautomerism: new challenges for electroactive ligands," European Journal of Inorganic Chemistry, no. 15, pp. 2957-2971, 2005.

[25] O. Rotthaus, F. Thomas, O. Jarjayes, C. Philouze, E. Saint-Aman, and J.-L. Pierre, "Valence tautomerism in octahedral and square-planar phenoxyl-nickel(II) complexes: are imino nitrogen atoms good friends?" Chemistry: A European Journal, vol. 12, no. 26, pp. 6953-6962, 2006.

[26] W. Kaim and B. Schwederski, "Cooperation of metals with electroactive ligands of biochemical relevance: beyond metalloporphyrins," Pure and Applied Chemistry, vol. 76, no. 2, pp. 351-364, 2004. 

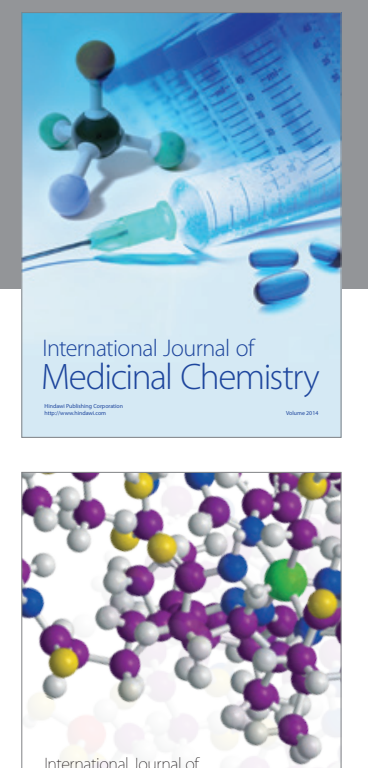

\section{Carbohydrate} Chemistry

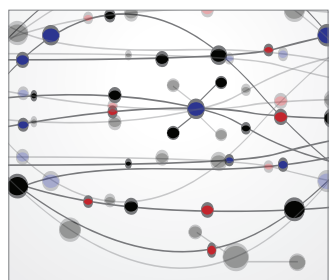

The Scientific World Journal
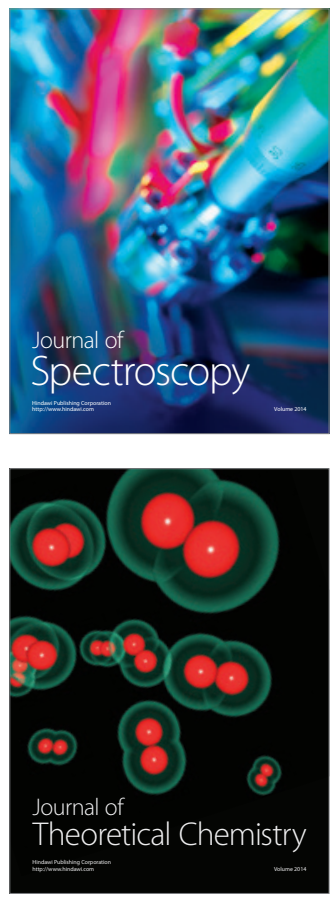
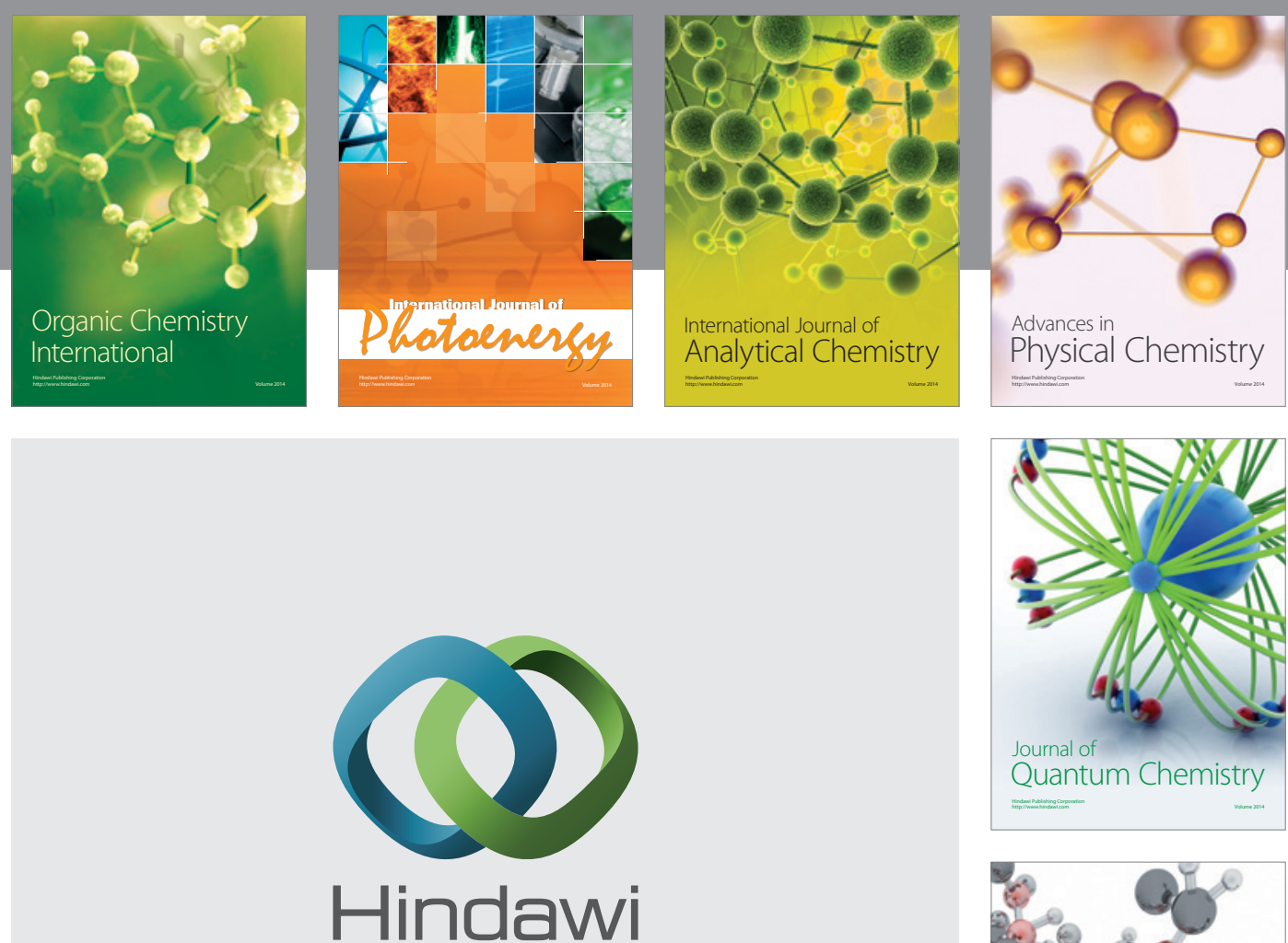

Submit your manuscripts at

http://www.hindawi.com

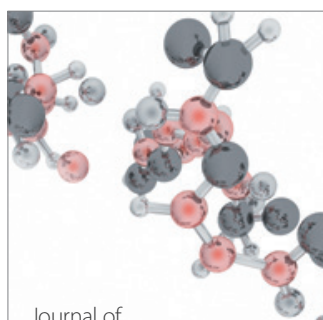

Analytical Methods

in Chemistry

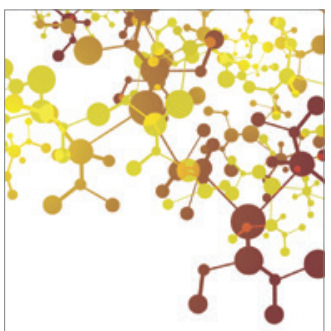

Journal of

Applied Chemistry

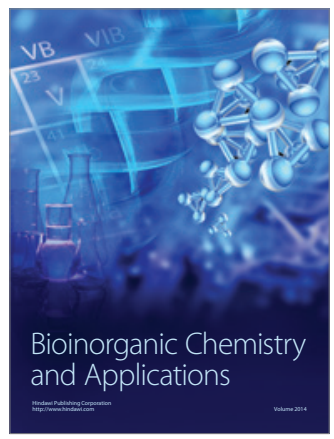

Inorganic Chemistry
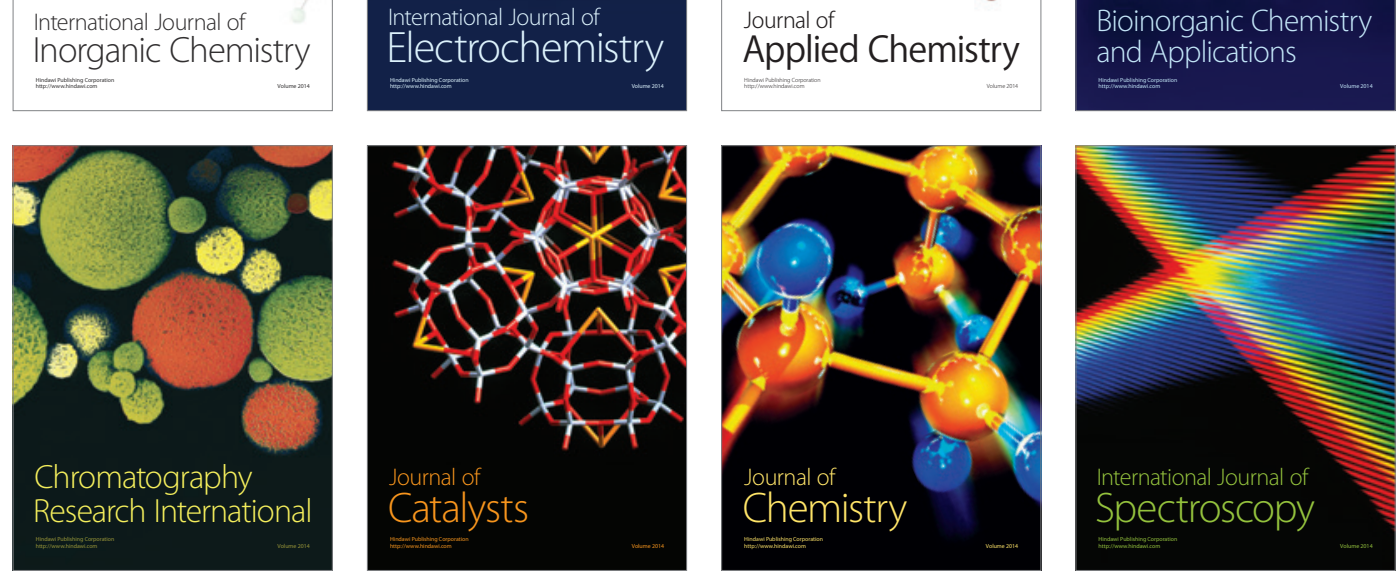